\title{
Examining the use of Glaser and Strauss's Version of the Grounded Theory in Research
}

\author{
Mariann Edwina, Sakenya D. McDonald
}

\begin{abstract}
This article focuses on the use of the Grounded theory $(G T)$ in English language acquisition related researches. It will deeply discuss the processes that take place when research is conducted using GT and compare the most prominent types of GT, as introduced by Glaser and Strauss. Although there have been few discussions on how the two types differ, this article will elucidate the differences on how they are used. This article also investigates all possible GT processes or steps providing in-depth explanation for each step. It is crucial for researchers to determine the type of GT that is suitable for their study and the steps to be followed as there are many differences in the two types. As observed in many studies, this article will also discuss the advantages and limitations of using the GT. It is prominent that most researchers use GT to conduct their research for a long duration to get in-depth information to form a grounded or proved theory. Later, follow up studies are usually conducted to test the theory that has been found. Therefore, knowing what takes place in the GT and grasping the recommendation that will be given to use it effectively will help researchers plan and conduct their studies related to GT resourcefully
\end{abstract}

Index Terms: Grounded Theory Method, Glaserian, Straussian

\section{INTRODUCTION}

Grounded theory (GT) is a qualitative research methodology that researchers use when they seek to define individual or shared human experiences. Marshall and Rossman (1999) wrote that qualitative research methods share the following similarities:

1. Qualitative research focuses on everyday life experiences

2. Qualitative research values participants' perspectives

3. Qualitative research supports inquiry as interactive process between researcher and respondents

4. and

5. Qualitative research centers around words and descriptions of experiences

In the late 1960's, sociologists Barney G. Glaser and Anselm L. Strauss wanted to construct a new qualitative model for conducting research. Glaser and Strauss argued that theories dominating sociological research did not allow for the construction of theory or were too rooted in positivist, or science-driven, processes. Glaser and Strauss' model, grounded theory methodology (GT or GTM), proposed a new way of moving emergent data to theory. In 1967, The

Revised Manuscript Received on 14 September, 2019.

Mariann Edwina, Universiti Pendidikan Sultan Idris , wina_e29@gmail.com

Sakenya D. McDonald, Prescott College, Arizona
Discovery of Grounded Theory, introduced Glaser and Strauss' methodology which has been utilized by researchers in fields ranging from nursing to sociology and psychology. From its introduction, GT has undergone numerous revisions and critiques and accordingly, has developed into both a method and a methodology. In other words, GT serves as both a way to conduct research, as well as, a research position or stance.

One of the most prominent shifts in GT occurred when Glaser and Strauss discovered that they had differing notions about role and function of analysis in research incorporating GT methods (Glaser et al, 2013, Cooney, 2010). In 2010, Cooney explained that Strauss worked with Juliet Corbin to improve the method by introducing open, axial, and selective coding, as explained in the first edition of their book. In the second edition, Strauss \& Corbin (1998) modified their initial approach of data analysis by pointing out that it had not been their intention to promote rigidity but to suggest guidelines or suggested techniques that would be most successful when utilizing GT methods in research. For example, consider that in Strauss and Corbin's recent editions $(2008,2015)$ both the researchers affirmed that qualitative analysis, especially as presented in GT, is flexible and fellow researchers were encouraged to consider their experiences and positions as researchers and how these subjectivities would inform the data collection process. Another effective critique of GT was presented by Kathy Charmaz and is currently known as constructivist grounded theory (CGT). Charmaz's interpretation of GT follows Strauss and Corbin's about the personalization of the research process and how researchers influence, even subconsciously, how data is collected and analyzed. It is crucial for researchers to identify which iteration of GT is most appropriate to their research goal by scrutinizing the advantages and limitations while simultaneously retaining an awareness of their position as a researcher, including bias, positionality, and driving inquiry.

\section{COMPARISON BETWEEN GLASER'S AND STRAUSS'S GTM}

Initially, Barney G. Glaser and Anselm L. Strauss sought to refocus qualitative research, specifically, research related to healthcare in the United States and how providers managed phenomenological processes such as illness, death, and dying. Glaser and Strauss wrote in that a defining feature of their new approach was that it could be considered

Blue Eyes Intelligence Engineering \& Sciences Publication 
as, "a general method of constant comparative analysis" (p.7) Furthermore, according to Charmaz (2014), "as they constructed their analyses of dying, they developed systematic methodological strategies that researchers could adopt for studying many other topics" (p.6).). In other words, Glaser and Strauss postulated that through logical analysis and comparison of systematically collected data, theory would emerge and be constructed.

Currently, there are three primary versions of GT that are the most accepted and recognized methodologies (McCallin, 2004). According to McCallin these include three core interpretations: Glaser, Strauss and Corbin, and Charmaz. Although all of these are still referred to as GT, it has been suggested that as the method has evolved so dynamically it would not be inappropriate to consider bisecting alternative interpretations into methodologies separate from the original Glaser and Strauss version. Glaser and Strauss (1967, Charmaz, 1995, p. 28) identified the distinguishing characteristics of grounded theory as:

1. Simultaneous involvement in data collection and analysis phases of research;

2. Creating analytic codes and categories that are developed from data, not from preconceived hypothesis;

3. The development of middle-range theories to explain behavior and processes;

4. Memo-making;

5. Theoretical sampling;

In 2011, Jones and Alony conducted a study and compiled a more updated table illustrating the differences between the Glaserian and Straussian GT.

Table 1: Comparison of the Glaserian and Straussian in Grounded Theory Approach (Jones \& Alony, 2011)

\begin{tabular}{|c|c|}
\hline 'GLASERIAN' & 'STRAUSSIAN' \\
\hline $\begin{array}{l}\text { Beginning with general } \\
\text { wonderment }\end{array}$ & $\begin{array}{c}\text { Having a general idea of } \\
\text { where to begin }\end{array}$ \\
\hline $\begin{array}{c}\text { Emerging theory/neutral } \\
\text { questions }\end{array}$ & $\begin{array}{l}\text { Forcing the } \\
\text { theory/structured questions }\end{array}$ \\
\hline $\begin{array}{l}\text { Development of a } \\
\text { conceptual theory }\end{array}$ & Conceptual description \\
\hline $\begin{array}{l}\text { Theoretical sensitivity (the } \\
\text { ability to perceive } \\
\text { variables and } \\
\text { relationships) comes from } \\
\text { immersion in the data }\end{array}$ & $\begin{array}{l}\text { Theoretical sensitivity } \\
\text { comes from methods and } \\
\text { tools }\end{array}$ \\
\hline $\begin{array}{c}\text { The theory is grounded in } \\
\text { the data }\end{array}$ & $\begin{array}{l}\text { The theory is interpreted by } \\
\text { an observer }\end{array}$ \\
\hline $\begin{array}{l}\text { Credibility, or verification, } \\
\text { of theory is derived from its } \\
\text { grounding in the data }\end{array}$ & $\begin{array}{l}\text { Credibility of theory comes } \\
\text { from the rigour of the } \\
\text { method }\end{array}$ \\
\hline
\end{tabular}

Based on Jones and Alony's comparative assessment of GT, it is notable that Strauss stressed that there should be a general idea of what the researcher wants to identify when data is being collected. On the other hand, Glaser highlighted that there is no need for prior assumptions; thus, the researcher usually has less or no knowledge on what to expect from participants. Since Strauss's method states that there is a need to have a general idea of where to begin, this further explains the need to force the theory with structured questions. Strauss also introduced the term conceptual description by defining it as a process of describing situations that lead the phenomena that is being examined. Alternatively, Glaser expressed that theories are derived from the concepts that are introduced in the data, naming it conceptual theory.

Referencing Jones and Alony's table, it is observed that Glasser and Strauss were of different interpretations on the topic of theoretical sensitivity. Both methods practice theoretical sensitivity, or the ability to define meaning from data combined with the capacity to understand what is relevant from anything that is not relevant in the investigation (Jones \& Alony, 2011). According to Glaser (2013), sources where the implementation of theoretical sensitivity may be appropriate include literature, professional experience, personal experience and analytic process. Glaser also stressed that the credibility or verification of theory is rooted in data and that relevance, in relationship to accuracy, is derived from existing data. On the contrary, Strauss emphasized that the credibility of theory is informed by the method and appropriateness of the method used to collect the data (i.e., using a focus group method when a structured interview method may have produced more desirable results) and that through analysis and interpretation of information an observer is then able to determine, based on subjective observations, if the theory is sound or in need of additional evaluation.

To further expand his method, Strauss emphasised that basic social processes need not be identified, which means that the analysis is even more flexible where they encourage researchers to construct processes based upon individual needs (Strauss \& Corbin, 2008, 2015). In doing so, Strauss believes that the researcher should remain active in acquiring the data by asking semi-structured questions to be answered by the participants. According to Nolas (2011), open-ended questions allow participants to "describe an experience, an action, or a process" (p.29) and encourage a discussion-type interview. 
Strauss emphasized a new model for discovery and theory development which was based on pragmatism, symbolic interactionism, and reflexivity (Nolas, 2011).

In contrast, Glaser explained that a basic social process should be identified, and the researcher should remain passive when collecting data. Glaser's approach emphasized "the emergence of theory from the data without the imposition of the analyst's conceptual category onto the data" (Nolas, 2011, p. 17). This positivist approach is suitable for studies where formal theory is the goal, informed by realist, objectivist assumptions, and where researchers intend to observe and interpret participant behaviour from the 'outside' (Charmaz, 1995, p. 31). Finally, Strauss claimed that through his method, the data may reveal the theory whereas Glaser maintained that data is planned or structured to reveal the theory. Glaser and Strauss originally intended GT as a methodology to be used to generate, elaborate upon, or modify theory by simultaneously comparing and analysing existing data. However, Glaser's claim suggested that similar to other qualitative methods, grounded theory is structured and driven by data collection and analysis.

Charmaz (2011) observed that Glaser's GT was more rooted in rigorous, quantitative training as demonstrated through Glaser's position on epistemology, in addition to, a logical and systemic approach to data analysis and therefore, represented the positivist perspective. This implies that theories are to be understood and accepted as social rules and these theories are valid because they are enacted or represented by reliable participants from existing situations. Conversely, Strauss' approach is from a pragmatist's perspective which, like constructivist GT, represents a perspective that "is inherently social and does not separate individuals from the social realities in which they exist" (Charmaz, 2017, p. 38). Furthermore, pragmatism is defined as a way of clarifying the contents of hypotheses by tracing their 'practical consequences', as well as offering ways to critically analyze the epistemological and ontological assumptions.

Much like Strauss' pragmatic GT approach, constructivist GT encourages critical analysis but also, "offers ways of doing it" (Charmaz, 2017, p. 34). Charmaz argued that Glasser and Strauss's respective views about GT assumed an objective reality position, assigning "an objectivist cast" to GT which, according to Charmaz, conflicts with constructivism's belief in the subjectivity of reality. Charmaz (2008) postulated that an objectivist grounded theory stance assumes the researcher takes a neutral, value-free position that only allows for limited knowledge, positions, and perspectives. Thus, Charmaz advocated a constructivist approach to GT that assumed multiple social realities and does not support the view that theories are discovered, but believes that the studied phenomena needs to be portrayed in an interpretive way because the interviewee and researcher embark together on the process of constructing reality (Gorra, 1999)

\section{IN- DEPTH ANALYSIS OF THE COMPARISON}

Table 2: Comparison of Glaserian and Straussian Ways of Analysis (Onions, 2006, pg 8-9)

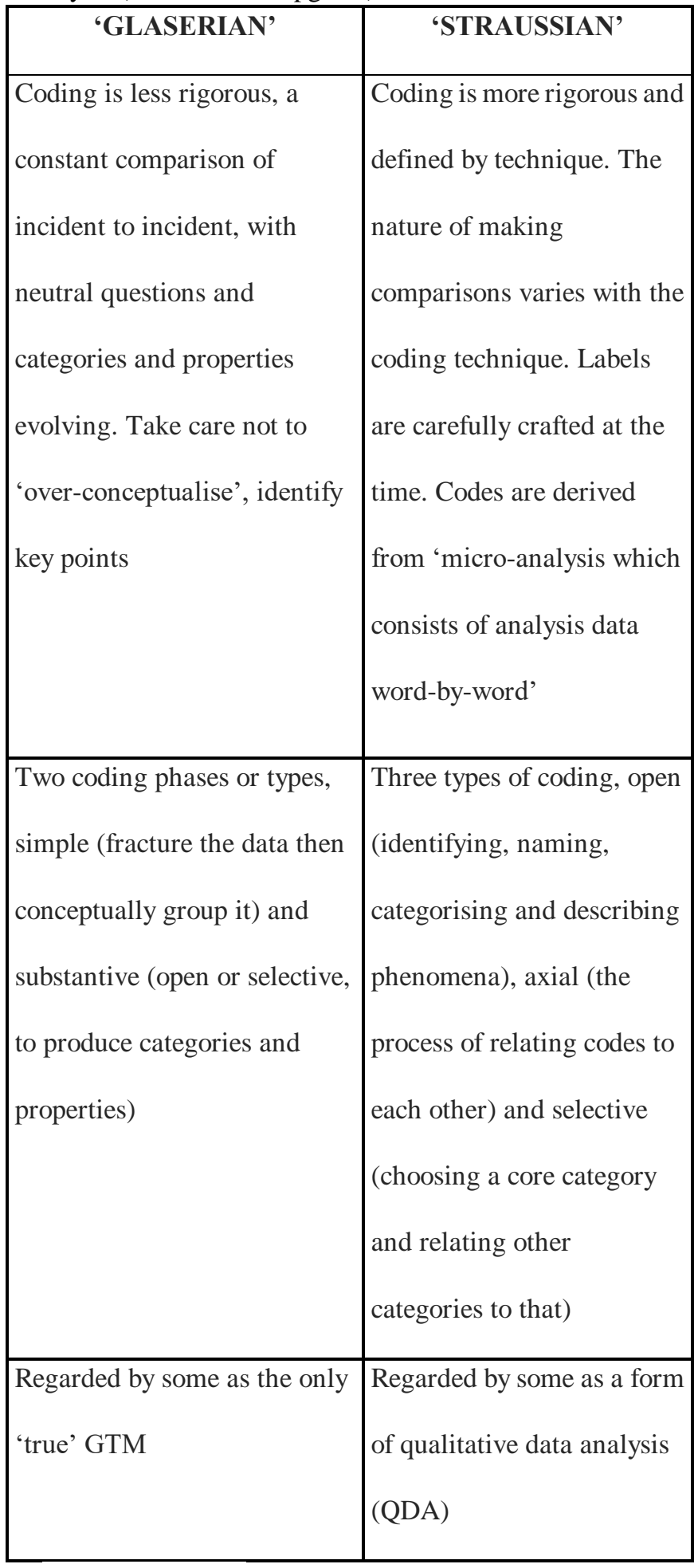

Table 2 compares the Glaserian and Straussian ways of analysing data and it is notable that the Straussians method is more practical and reliable in obtaining data to construct a theory. GT also postulates that research should be done by mainly involving the practitioners of the subject matter. In contrast, a researcher could also extract theories by looking at past literature, however, it is perceived from studies done using the GT that by doing so, the researcher may face the risk of obtaining information that are not proven and

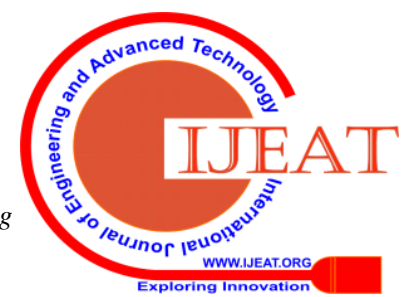


inconsistent.

As shown in figure 1, there are several stages that are involved in grounded theory (Lawrence \& Tar, 2013):

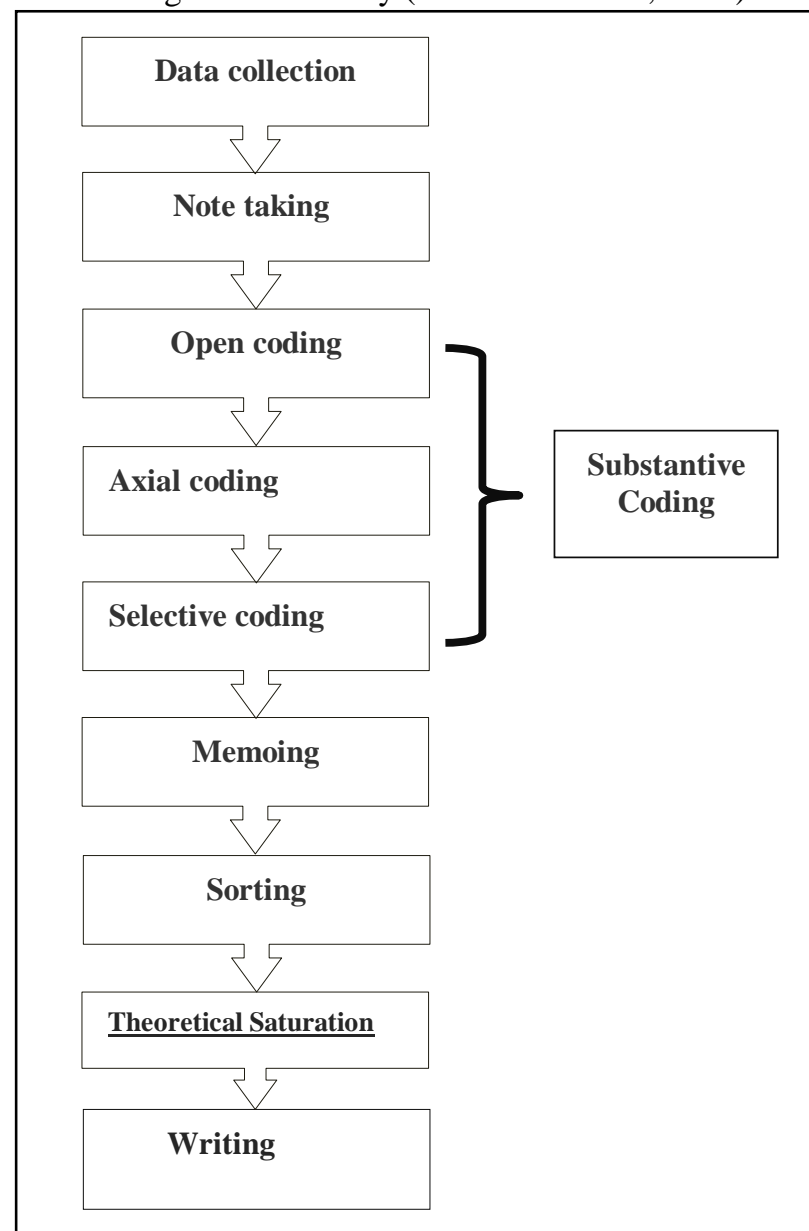

Fig 1: Stages in Grounded Theory (Lawrence \& Tar, 2013)

The flow in Figure 1 presents the stages of GT from inception to conclusion beginning with an overarching introduction to the subject matter. According to Dey (1999) the first stage is observation and critical thinking about a phenomenon, problem, or existing theory. This process may introduce a problem, such as infrastructural flaw or societal defect, and then through iterative processes a researcher will gradually focus their interests to the point of constructing a more specific hypothesis. Once a hypothesis has been formulated, a researcher will identify what data sets are desired and begin collecting by implementing appropriate methods. In qualitative studies, these methods may include open-ended interviews and transcriptions, observations, literature reviews, and surveys or focus groups.

For example, one method includes note-taking or the process of writing and recording important observations with the intention of collecting, coding, and cataloguing data. Oftentimes, note-taking is used interchangeably with the term coding which begins after the first-hand data are collected and this includes categorizing the data to show numerous issues that are to be studied. Glaserian GT uses three levels of coding including: open coding, selective coding, and theoretical coding. In contrast, the Straussian GT introduced substantive coding that also comprises three levels which are open coding, axial coding and selective coding. In substantive coding, data are organised and coded as soon as they are collected. In the open coding process, collected date are examined and coded through a process which breaks the information into smaller categories. The process of open coding examines every single category without restrictions or applying any filters, therefore making all data acceptable. These integrated data are accumulated and organised to form groups of similar occurrences.

For instance, when data from an interview, questionnaire or documents are studied, all information from these three different resources are broken down and grouped into similar categories. This will allow the researcher to look for patterns that may lead to subsequent interest. As small data begin to fill the categories, those that are most dense become known as core categories (Glaser, 2013). Open coding employs a process of constant comparison and with Straussian GT, the process of constant comparison is closely associated with axial coding. These two terms that occur in Glaserians and Straussians GT represent a thoroughly systematic way of collecting and sorting data which facilitates a concurrent and synchronised process of coding and analysis (Partington, 2000).

As categories start to gather and expand, constant comparison requires the researcher to begin to reflect on the data and start hypothesizing. This is usually done by using memos to record the researchers' perceptions of the data, such as reflections and initial observations, which leads to a hypothesis and theory construction. Axial coding may be implemented at this point specifically because axial coding encourages the researcher to look for and identify links between the categories for the purpose of building themes. All initial data that is categorised and labelled as core are grouped separately and linked to each other. A core category is a category that both represents major concerns of the participants and is used to build relationships between participant-initiated themes. Generally, this is a common way to show the cause and effect relationship that exist between the groups.

Next, selective coding is attained when core categories become noticeable. Selective coding refines the data filtering process filter by only considering categories that are believed to be more relevant to the emerging of theory or hypothesis. Therefore, only the most valid and relevant passages of the transcript are used and coded. To facilitate this, interview questions are continuously reformulated to encompass the new and more focused direction of the research. Also, in the selective coding process that was generated by Strauss \& Corbin (2008), data that are being coded, compared, and accumulated to form categories and core categories are involved in the process of sampling which is known as theoretical sampling, a term that is very prevalent in Glaserian GT.

Theoretical sampling includes the process of finding and focussing on newer targets or participants for further data collection process. Newer targets or participants are identified or introduced by the previous participant. The goal is to systematically select new participants or respondents that will guide the researcher to

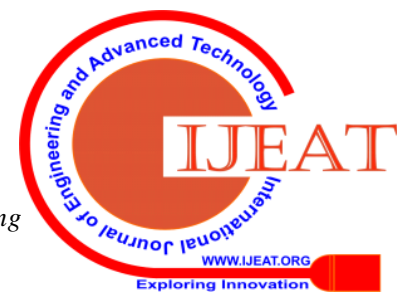


select data samples which are most significant and lead the research to progress. Theoretical sampling works by picking subsequent participants based on the information which emerges from the data that had already been coded (Sarantakos, 2005). This process ensures that the new data contributes to the theory development and that they work with the concepts that are already compiled through a measure of fit and relevance (Glaser, 1978).

Next, the memoing stage refers to the process of recording or making notes about any theoretical hypotheses that arise from the coding. This leads to the construction of theories from various categories and themes that have emerged from the data as a result of the coding process. It also allows the identification of links between the various categories and themes to be outlined and presented, which allows theory to emerge clearly and precisely. Glaser refers to memoing as the core stage in the process of generating theory (Glaser, 1978, pp.62-65). He added that memos have four basic goals:

1. They should develop ideas and codes

2. These ideas should develop freely

3. Should be stored centrally

4. Should be sortable

Correspondingly, several theoretical hypotheses will emerge from the data through the coding process. Theoretical hypotheses are made to clearly show the relationships between variables that are about to be studied. Finally, the process of sorting data is conducted. Sorting is also known as theoretical coding, the most abstract level of coding as in Glaserian GT (Gorra, 1999). Theoretical coding occurs when core categories have become saturated. Saturation happens when the researcher keeps on collecting data until he/she receives only already known statements (Selden, 2005). Hence, the point of saturation is accepted as a point that is reached when no new data rises or is developed from additional data collection. Lastly the researcher will begin the writing process when all data are organised, and a narrow theory or hypothesis is produced.

\section{CONCLUSION}

According to Nolas (2011), Glaser and Strauss eventually developed "separate intellectual trajectories" (p. 17), as referenced earlier, and these trajectories resulted in two distinct schools of thought on GT. Nolas (2011) suggested that Glaser's approach seemed to retain a more positivist view where the emphasis was placed on developing 'formal theory" "without the imposition of the analyst's conceptual categories into the data" (p.17). By contrast, Strauss took a constructivist approach to GT, one inclusive of symbolic interactionism, or the theory that identities and situations are transactional process constructed through human interactions. In other words, Glaser's approach to GT was driven by the notion that the researcher should remain removed from the process of collecting and analyzing data whereas Strauss, and later Charmaz, both argued that it is the researcher that drives the process and therefore, constructs the data collection and analysis process.

In doing so, Strauss believed that the researcher should remain active in acquiring the data by asking semi-structured questions to be answered by the participants. According to Nolas (2011), open-ended questions allow participants to "describe an experience, an action, or a process" (p.29) and encourages a discussion-type interview. Strauss believed and emphasized a new model for discovery and theory development which was based on pragmatism, symbolic interactionism, and reflexivity (Nolas, 2011).

In contrast, Glasser encouraged researchers to recognize social processes and commit to passivity in the collection and analysis of data. Glaser's approach emphasized "the emergence of theory from the date without the imposition of the analyst's conceptual category onto the data" (Nolas, 2011, p. 17). This positivist approach is suitable for studies where 'formal theory' is the goal, informed by realist, objectivist assumptions, and where researchers intend to observe and interpret participant behaviour from the 'outside' (Charmaz, 1995, p. 31). Charmaz argued that Glasser and Strauss's respective views about GT assumed an objective reality position, assigning "an objectivist cast" to GT which, according to Charmaz, conflicts with constructivism's belief in the subjectivity of reality. Charmaz (2008) postulated that an objectivist grounded theory stance assumes the researcher takes a neutral, value-free position that only allows for limited knowledge, positions, and perspectives.

Most researchers find that grounded theory is an excellent way for identifying emergent data, or data that presents after careful analysis of various collection methods including coding, interviewing, and memo-taking. Utilizing this emergent data, researchers are then able to recognize patterns and, if applicable, reconstruct or further develop theory. Also a key point that is vital in GT is that the saturation process. The saturation process utilized in GT differs from other qualitative forms of analysis in that GT does not require multiple levels of triangulation for validation (Mertens, 1998) but rather, uses emergent data and new categories to build a systematic case.

\section{REFERENCES}

[1] Charmaz, K. (1995). The Search for Meanings - Grounded Theory. In J.A. Smith, R. Harre' \& L. Van Langenhove (Eds.), Rethinking Methods in Psychology (pp. 27-49). London: Sage Publications.

[2] Charmaz, K. (2008). Constructionism and The Grounded Theory Method. In J.A. Holstein \& J. F. Gubrium (Eds.), Handbook of Constructionist Research (pp. 397-412). New York: The Guilford Press.

[3] Charmaz, K. (2014). Constructing Grounded Theory (2nd ed.) Thousand Oaks, CA: Sage Publications.

[4] Charmaz, K. (2017). The Power of Constructivist Grounded Theory for Critical Inquiry. Qualitative Inquiry, 23(1), 34-45. doi:10.1177/1077800416657105

[5] Dey, I. (1999) Grounding Grounded Theory, Academic Press, San Diego, CA.

[6] Glaser, B. G., \& Strauss, A. (1967). The discovery of grounded theory: Strategies for qualitative research. New York: Aldine.

[7] Glaser. (2013). Grounded theory methodology. Intr19oducing Qualitative Research in Psychology, 69-82.

[8] Glaser, B. G. (1978). Theoretical sensitivity: Advances in the methodology of grounded theory. Sociology $\mathrm{Pr}$. https://doi.org/Casa

[9] Gorra, A. (1999). Chapter 3 Research Methodology Grounded theory methodology - an overview. PHD - Grounded Theory, 86-115. https://doi.org/ISSN 1943-7765 
[10] Jones, M., \& Alony, I. (2011). Guiding the use of grounded theory in doctoral studies - An example from the australian film industry. International Journal of Doctoral Studies, 6, 95-114. https://doi.org/ISSN 1943-7765

[11] Lawrence, J., \& Tar, U. (2013). The use of Grounded Theory Technique as a Practical Tool for Qualitative Data Collection and Analysis Department of Applied Computing and Information Technology Department of Politics \& International Relations. Electronic Journal of Business Research Methods, 11(1), 29-40. https://doi.org/10.1080/10548408.2014.883346

[12] Marshall, C., \& Rossman, G. B. (1999). The "what" of the study: Building the conceptual framework. Designing qualitative research, 3(3), 21-54.

[13] McCallin, A. (2004). Pluralistic dialoguing: A theory of interdisciplinary teamworking. The Grounded Theory Review, 4, 25-42.

[14] Nolas, S. M. (2011). Grounded Theory Approaches. In N. Frost, Qualitative Research Methods in Psychology: Combining core approaches (pp. 16-43). New York: McGraw-Hill.

[15] Onions, P. E. (2006, May). Grounded theory applications in reviewing knowledge management literature. In Leeds Metropolitan University Innovation North Research Conference. Leeds, UK.

[16] Partington, D. (2000). Building grounded theories of management action. British Journal of management, 11(2), 91-102.

[17] Sarantakos, S. (2005). Varieties of social research. In Social research, $3 r d$ ed (pp. 28-52). https://doi.org/10.1007/978-1-349-14884-4_2

[18] Selden, L. (2005). On Grounded Theory-with some malice. Journal of Documentation, 1(61), 114-129.

[19] Strauss, A., \& Corbin, J. (1998). Basics of Qualitative Research: Techniques and Procedures for Developing Grounded Theory. Basics of Qualitative Research Grounded Theory Procedures and Techniques (Vol. 3rd editio). https://doi.org/10.4135/9781452230153

[20] Strauss, A., \& Corbin, J. (2008). Strauss, A., \& Corbin, J. (1990). Basics of qualitative research: Grounded theory procedures and techniques. Newbury (Vol. 3). https://doi.org/10.4135/9781452230153

\section{AUTHOR'S PROFILE}

Mariann Edwina, Affiliated with Universiti Pendidikan Sultan Idris. The research areas include Grounded Theory.

Sakenya D. McDonald, Prescott College, Arizona. The research areas include religion and nature, power and powerlessness and environmental identity development in marginalized persons. 